\title{
CIDADANIA E EDUCAÇÃO ENQUANTO VALOR ECONÔMICO: POR UMA PERSPECTIVA DIFERENCIADA
}

\author{
Lilian Tatiane Candia de Oliveira ${ }^{1}$ \\ Paulo Gomes Lima ${ }^{2}$
}

\begin{abstract}
RESUMO
Esse texto discute a cidadania enquanto valor econômico, condicionada por contextos do modo de produção e força de trabalho considerando a educação como eixo transversal em três momentos. O primeiro trata da ideia de cidadania a partir do processo de reestruturação produtiva no Brasil, o que impulsiona a discussão do segundo momento sobre a tipologia do cidadão a ser formado e para qual sociedade. A inserção da escola como agência formadora da construção cidadã à luz da racionalidade econômica configurase o terceiro eixo. Trata-se de um estudo reflexivo de natureza qualitativa, cujo destaque se dá para as recorrências que o mercado solicita na formação de tipologias de cidadania adequadas à sua retroalimentação.
\end{abstract}

Palavras-chave: cidadania; escola; valor econômico.

\section{CITIZENSHIP AND EDUCATION WHILE ECONOMIC VALUE: FOR A DIFFERENT PERSPECTIVE}

\begin{abstract}
This paper discusses the economic value as citizenship, conditioned by production contexts and the workforce considering education as a transaxle in three times. The first deals with the idea of citizenship from the productive restructuring in Brazil, what drives the discussion of the second moment about the typology of the citizen to be formed and why society. The insertion of the school as forming citizen construction agency in the light of economic rationality is the third axis. It is a reflective study of qualitative nature, whose prominence is given to the recurrences of the market calls for the formation of appropriate citizenship to its types of feedback.
\end{abstract}

Keywords: citizenship; school; economic value.

\section{Introdução}

Embora se tenha uma perspectiva ideal de cidadania como vivência e participação plena na vida da sociedade, garantidos os direitos políticos, civis e sociais em seu sentido pleno; diversos outros sentidos podem ser observados na dimensão do valor e intencionalidade da tessitura social, o que necessariamente não se afasta da discussão sobre o modo de produção e força de trabalho que mobilizam os compassos da tipologia de cidadania necessária à sua estrutura, o que passa a fazer diferença no papel que a escola e a educação devem desempenhar.

Um dos sentidos que se destaca nesse texto é o da cidadania enquanto valor econômico referindo-se à sobreposição das questões econômicas em relação às demais facetas sociais, fazendo com que o cidadão seja comparado a um mero cliente, ou, um consumidor dos serviços estatais. (MARTINS, 2001). Mas, isso ainda não seria tudo, pois se a cidadania em seu sentido democrático tem como finalidade a promoção da igualdade 
de direitos diante da lei, bem como de igualdade de participação política e condições socioeconômicas básicas como eixos que promovem a dignidade humana (BENEVIDES, 2007), na dimensão do valor econômico esse encadeamento é reduzido, provocando uma "mutilação de cidadania", ainda que se defendesse de forma explícita o seu sentido universal.

Nesse âmbito, a escola e a educação, que deveriam ser promotoras de importante processo formativo para a desalienação e construção do sentido universal da cidadania numa perspectiva democrática "[...] transmite um quadro que legitima os interesses dominantes" (MÉSZAROS, 2005, p.15), portanto, fornece à maquinaria capitalista o instrumental necessário para a sua manutenção e desenvolvimento, a despeito de significativas modificações no contexto das políticas públicas educacionais elaboradas e implementadas para fazer valer o direito de todos e para todos.

Este texto discute a cidadania enquanto valor econômico, condicionada por contextos do modo de produção e força de trabalho considerando a educação como eixo transversal em três momentos. O primeiro trata da idéia de cidadania a partir do processo de reestruturação produtiva no Brasil, o que impulsiona a discussão do segundo momento sobre a tipologia do cidadão a ser formado e para quê sociedade. A inserção da escola como agência formadora da construção cidadã à luz da racionalidade econômica configurase o terceiro eixo.

\section{A cidadania e os eixos do processo de reestruturação produtiva.}

A cidadania de acordo com Marshall (1967) é o ato de participar da vida política garantindo-se o mínimo de alcance dos direitos sociais, políticos e civis, contudo quando se fala em participação da/na vida social, que pressupõe direitos e deveres, é muito delicado dar-se por universalizado o que se toma por "parte" ou mínimo a ser "oferecido", dado o sentido de totalidade que a cidadania propriamente dita evoca. No mundo em que a renda dos 500 bilionários mais ricos, supera a dos 416 milhões de pessoas mais afetadas pela pobreza do planeta (PNUD, 2007), há que se problematizar o olhar fragmentado e fragmentário sobre o conceito de cidadania que, o reduz às medidas de varejo tirando de foco ou marginalizando a desigualdade social como um dos eixos que o fragiliza.

Um ponto que favorece a compreensão desse olhar, considerando a realidade brasileira pode ser observado em meio ao processo de reestruturação produtiva e as exigências de formação de uma tipologia de cidadania pertinente que pudesse acompanhar as mudanças no âmbito do mercado. É oportuno destacar que em meio aos discursos internacionais que defendiam uma solidarização internacional pela diminuição da pobreza e desigualdades sociais, a estrutura e intencionalidade do capitalismo permancera inalterável (LIMA, 2012). Vale compreender tal contexto.

No século passado, ao findar a década de 1970 o capitalismo mundial entra em crise, devido à exaustão do modelo de acumulação taylorista/fordista, do Estado de bemestar social. Essa crise afetou várias partes do mundo de maneiras e graus diferenciados, não importando quais fossem suas configurações políticas, sociais e econômicas. (HOBSBAWM, 2005).

Nesse sentido, os Estados organizaram-se buscando novas formas de enfrentamentos, o que culminou em um novo estágio do capitalismo global, caracterizados pela "[...] mundialização ou transnacionalização do capital, a financeirização da economia, a reorganização produtiva de bases flexíveis, a remodelação da estrutura de poder e as novas formas de organização e gestão, tanto no setor privado quanto no público" 
(CARVALHO, 2009, p.1140) que pode ser denominado toyotismo ou ponto instrumental da reestruturação produtiva.

Contudo, essa nova prática pode ser considerada um estágio superior de racionalização do trabalho em que não ocorre, radicalmente, uma ruptura com as práticas do taylorismo/fordismo.

Sendo assim, segundo Alves (2007), alguns autores o denominam "neofordismo". Esse autor expõe que o toyotismo, ou reestruturação produtiva promove uma via original de racionalização do trabalho em que este é organizado, o concomitantemente a produção capitalista como um todo, para se adequar as novas tecnologias, as máquinas de automação flexível. Contudo explicita que o toyotismo não pode ser caracterizado como uma nova forma produtiva, apenas representa uma adequação às novas tecnologias da grande indústria. Assim a reestruturação produtiva caracteriza-se como um novo arranjo na estrutura e organização da produção, culminando num padrão denominado acumulação flexível. Esse padrão possui características muito peculiares, isto é:

[...] marcada por um confronto direto com a rigidez do fordismo. Ela se apóia na flexibilidade dos processos de trabalho, dos mercados de trabalho dos produtos e padrões de consumo. Caracteriza-se pelo surgimento de setores de produção inteiramente novos, novas maneiras de fornecimento de serviços financeiros, novos mercados e, sobretudo, taxas altamente intensificadas de inovação comercial, tecnológica e organizacional. [...] permitem que os empresários exerçam pressões mais fortes de controle do trabalho sobre uma força de trabalho de qualquer maneira enfraquecida por dois surtos selvagens de deflação, força que viu o desemprego aumentar nos países capitalistas avançados para níveis precedentes no pós-guerra. (HARVEY, 2000, p. 140).

No Brasil, esse processo de modificação na estrutura da produção, ocorreu, de acordo com Leite (1995 apud MARTINS, 2001), em pelo menos três momentos: o primeiro teve início ainda na década de 1970 e prosseguiu até os anos 80, com uma marcante difusão dos círculos de qualidade; o segundo período, compreendido entre os anos de 80 e 90 foi marcado pela difusão de equipamentos e adoção de várias técnicas japonesas no que tange aos aspectos organizativos do trabalho (Just-intime, CEP, kanban, trabalho em células); e o último período que iniciou nos anos de 1990 em que as empresas enfatizaram as técnicas japonesas de gestão e organizacao, principalmente na flexibilização do trabalho e no maior envolvimento do trabalhador com a qualidade e a produtividade.

Nesse sentido, observa-se que as empresas têm buscado estratégias que venham atender as exigências da economia globalizada. Martins (2001) aponta que as empresas adquirem os produtos mais desenvolvidos tecnologicamente no intuito de trilhar os caminhos dos líderes de mercado. A inserção desses novos produtos eletrônicos exige um novo tipo de trabalhador, que seja mais qualificado, que tenha maior nível de escolaridade, e que assuma mais responsabilidades. Martins, também aponta que esse trabalhador deve estar mais comprometido com aquilo que a empresa objetiva.

O trabalhador está imerso nas relações sociais dominadas pelo capital, o que exige, de acordo com Ferreira Jr. e Bittar (2008), reflexões urgentes, principalmente sobre o contexto de sala de aula, da convivência de professores e alunos, uma vez que a escola, nesse momento de reestruturação produtiva, adéqua-se aos ditames do mercado, convertendo-se no espaço do não conhecimento e do esvaziamento do seu sentido.

O perfil exigido pelas empresas é de um trabalhador que seja "criativo e responsável, saiba resolver problemas, trabalhar em equipe, lidar bem com constantes Revista HISTEDBR On-line, Campinas, $n^{o}$ 54, p. 89-99, dez2013 - ISSN: 1676-2584 
inovações tecnológicas e que seja portador de uma alta capacidade de abstração que o predisponha a constante aprendizagem" (ZIBAS, 1997, p. 123).

Para isso, o controle da subjetividade é fundamental, que combinados a outros elementos, inclusive ideológicos, que enfraquecem o empoderamento dos sujeitos:

A preocupação fundamental do toyotismo é com o controle do elemento subjetivo no processo de produção capitalista, isto é, com a "captura" da subjetividade do trabalho pela produção do capital e com a "manipulação" do consentimento do trabalho através de um conjunto amplo de inovações organizacionais, institucionais e relacionais no complexo de produção de mercadorias, caracterizadas pelos principio de "automação" e de "auto ativação" [...] O toyotismo [...] opera a articulação hábil da "força" (destruição do sindicalismo industrial de massa) com a "persuasão" (remunerações flexíveis ligadas a desempenho individual e trabalho em equipe e intensa propaganda ideológica) [...]. (ALVES, 2007, p. 247, aspas do autor).

Assim, a forma de organização do trabalho toyotista difere-se do fordista principalmente porque no primeiro ocorre a subsunção formal-intelectual do trabalho ao capital, enquanto que no último ocorre a subsunção formal-material. Daí a necessidade de novas qualificações do trabalhador, que deve articular habilidades cognitivas e comportamentais. (LIMA, 2012, ALVES, 2007).

A exigência do capital, no que se refere ao perfil do trabalhador, tem impacto direto tanto nas políticas sociais, dentre elas a educação e concomitantemente no exercício da cidadania. Faz nos refletir em que medida o trabalhador é valorizado em face dos interesses supremos da economia, percebemos os direitos dos trabalhadores sendo reduzidos, percebemos a redução da proteção social, a diminuição dos salários e novas formas de redução de custos para as empresas, como, por exemplo, a implantação do banco de horas.

Essas mudanças no mundo do trabalho determinam as políticas de formação profissional, com influência nas políticas educacionais propiciando novas demandas para a escola, uma vez que "[...] é a partir de tais mutações orgânicas da produção capitalista na era da globalização que podemos compreender a constituição de um complexo ideológico que irá determinar as políticas de formação profissional, com seus conceitos significativos de empregabilidade e competência". (ALVES, 2007, p. 249). É a partir dessas transformações que podemos pensar de que forma ocorre o preparo e para que tipo de exercício de cidadania da nova classe trabalhadora em formação.

Lima (2012, p. 46) destaca que a década de 1990 foi marcada pela adoção dos pressupostos neoliberais que davam sustentação à reestruturação produtiva no governo Fernando Henrique Cardoso- FHC e a reforma do Estado. Essas ações culminaram em "[...] ordenamento substancial das políticas públicas para a educação brasileira, inclusive [...]" acerca da 'inclusão social' de classes menos favorecidas e grupos étnicos à universidade e demais modalidades de ensino, como já vinha sendo arquitetado entre as décadas de 1980 e 1990. O tom para a construção da cidadania em documentos oficiais e literatura de apoio era forjado pelo mercado, logo, os interesses do capital para a formação do cidadão eram revestidos de "humanidade" pelas oportunidades geradas, sem colocar como ponto de discussão a extinção da exclusão social e as desigualdades sociais como um todo.

\section{Tipologia de trabalhador para a sociedade capitalista}


$\mathrm{Na}$ antiguidade, era um processo entre homem e natureza, em que o homem no seu fazer mediava, regulava e controlava seu metabolismo com a natureza. Nesse o homem aciona sua força corpórea utilizando seus "braços, pernas, cabeça e mãos, a fim de se apropriar da matéria natural numa forma útil à própria vida. Ao atuar, por meio desse movimento, sobre a natureza externa a ele e ao modificá-la, ele modifica, ao mesmo tempo, sua própria natureza" (MARX, 1983, p. 149).

Frigotto (2009) salienta que as relações sociais e a própria existência humana compreendem centralmente a produção material, porém, abrangem linguagem, idéias, valores, etc. $\mathrm{O}$ autor acrescenta que os diferentes modos de produção, seja ele, tribal, medieval ou capitalista, sempre estão vinculadas a uma base material e, inevitavelmente, ao trabalho.

Por volta do século XV, devido a forte transação monetária, o feudalismo entra em crise e posteriormente em degradação. Isso porque, ao mesmo tempo, os grandes donos de terra iam passando a mercadores e seus antigos camponeses se tornando trabalhadores assalariados em decorrência do êxodo rural, em que os servos buscavam atingir melhor qualidade de vida nos centros urbanos. Imerso na crise, o feudalismo propicia o desenvolvimento do capitalismo mercantil, no qual a produção no campo, invadida pela variável comercial e as trocas, já objetivava a riqueza e o lucro. A divisão social do trabalho infiltra-se e se intensifica, principalmente pela ruptura da fiação e tecelagem, que se caracteriza como mola propulsora para novas e cada vez mais crescentes divisões do trabalho.

Do século XVII ao XIX, período do capitalismo concorrencial, inúmeros fatores contribuem para a afirmação da sociedade capitalista, com a emersão de unidades fabris de produção e importantes invenções. E, em 1640 e 1660, ocorre a Revolução Inglesa, o que proporcionou novos horizontes à política econômica e social e, concomitantemente, a livre expansão do capitalismo. O século XVIII ficou marcado na história e é palco de revoluções e aceleração dos antagonismos. Marco histórico da humanidade, a Revolução Francesa resultou em transformação social, política e econômica e que realiza no plano político a transição para o capitalismo. (MARTINELLI, 2006).

Nesse contexto, ocorre a afirmação do capitalismo enquanto sistema econômico, o que englobou inúmeras lutas, dentre elas política, ideológica e institucional. De um lado, os burgueses, e de outro, a nobreza e o clero (núcleo dominante no modo de produção feudal). A burguesia afirma-se como classe dominante, torna-se detentora dos meios e instrumentos de produção e da propriedade privada. Nesse sentido os camponeses são livres apenas para vender sua força de trabalho e é nesse contexto que se perpetua historicamente o embate das lutas de classe. (FRIGOTTO, 2009).

Contudo a sociedade burguesa aliena as relações sociais de produção, atuando como potência externa que domina, assegura e assevera a sociedade de classes, potencializa a exploração do trabalho e, concomitantemente, emergem as multifacetadas expressões da questão social.

No final do século XIX, logo após a Revolução Industrial, a produtividade da humanidade foi afetada. O sistema fabril ou sistema capitalista, com ímpeto ilimitado para a produção, levou a produção industrial a níveis que nunca haviam sido alcançados. Porém a custos muito elevados, pois, "[...] As pessoas idosas eram relegadas sem qualquer tipo de renda. Os trabalhadores eram relegados sem qualquer compensação quando deixavam de ser necessários. As mulheres, particularmente, eram exploradas. E também as crianças. [...]”. (GALBRAITH; MENCHIKOV, 1988, p. 68). 
Durante os séculos XIX e XX o capitalismo se renovava em suas crises cíclicas, sempre se utilizando de estratégias, como por exemplo, o Welfare State ou estado de bemestar social. Segundo Lombardi et al (2002), a partir de então o Estado passa a intervir na economia e lança mão de suas verbas para cobrir as deficiências dos gastos do setor privado, reduz impostos, aumenta os gastos públicos e combina medidas para o aumento da demanda e aumento de produção. Todas essas ações objetivam alcançar o pleno emprego, que após a Segunda Guerra Mundial alcança o período chamado de "idade de ouro". Essas são idéias fundamentais da Revolução Keynesiana.

No final do século XX, mas precisamente na década de 1970 o capitalismo entra novamente em crise devido a recessão mundial advinda do aumento dos preços do petróleo. Essa é caracterizada como uma "crise estrutural [...] tem sido objeto de consideração de vários autores que constatam o esgotamento de um ciclo de desenvolvimento capitalista. Mas o que existe hoje é a passagem para uma nova época histórica do capital com um novo modo de controle sócio-metabólico". (ALVES, 2007, p. 148).

Essa crise resulta na inserção do sistema neoliberal que afeta diretamente as políticas sociais e econômicas. O Estado passa a cortar gastos sociais e privatizar os sistemas públicos sociais, caracterizando-se como Estado Mínimo. A política neoliberal foi difundida mundialmente a partir do governo de Margareth Thatcher (Inglaterra, 1979) e Ronald Reagan (Estados Unidos, 1980). No Brasil as medidas neoliberais foram adotadas a partir da eleição do Fernando Henrique Cardoso na década de 1990. (ZANARDINI; ORSO, 2008).

De acordo com Ball (2011, p. 31) o neoliberalismo thatcherista propiciou o renascimento do individualismo competitivo e do novo tipo de cidadão "o consumidor". Esse cidadão "é animado por e articulado às concepções de liberdade de Hayek, da "liberdade de" mais do que da "liberdade para" e liga-se ao direito da escolha". Esse autor ressalta que a democracia do consumidor é o meio e o fim da mudança social e econômica que constrói a nova subjetividade.

Nesse cenário, que resulta em precariedade de trabalho e exclusão, o desemprego é que deve forjar o novo tipo de trabalhador embasado no modelo das competências em que os conhecimentos e habilidades apreendidos no contexto escolar devem ter uma utilidade prática e imediata, e devem estar vinculados aos objetivos e missão das empresas. De acordo com Alves (2007), a qualidade da formação do trabalhador é avaliada pelo seu fim último, ou seja, as competências e habilidades do trabalhador devem às necessidades da racionalização do sistema produtivo. Uma vez que o capital humano das corporações empresariais devem ser mobilizadas e atualizadas para garantir o diferencial ou vantagem competitiva.

O tipo de trabalhador da sociedade capitalista neoliberal da reestruturação produtiva é o engajado, estimulado, centralizado, assalariado, estável, que garanta a produção fluída e difusa, flexível, competitivo, atualizado, ter disposição subjetiva para cooperar com a produção, autoempreendedores, colaboradores externos, terceirizados, prestadores de serviços, com habilidades de comunicação necessárias para assegurar as redes de informação e equipes de trabalho.

\section{A escola e a cidadania enquanto valor econômico}

O aparato legal, mais especificamente a Carta Magna e a Lei de Diretrizes e Bases da Educação Nacional- LDBEN, tem como um de seus pressupostos fundamentais a formação dos estudantes para o exercício da cidadania. Assim, A Constituição Federal no 
Art. 205 expõe: “A educação, direito de todos e dever do Estado e da família, será promovida e incentivada com a colaboração da sociedade, visando ao pleno desenvolvimento da pessoa, seu preparo para o exercício da cidadania e sua qualificação para o trabalho". (BRASIL. CONSTITUIÇÃO FEDERAL. 1988, p. 34). No Art. $2^{\circ}$ da Lei 9394/96 que estabelece as Diretrizes e Bases da Educação Nacional: "a educação [...] tem por finalidade o pleno desenvolvimento do educando, seu preparo para o exercício da cidadania e sua qualificação para o trabalho". (BRASIL. LDBEN, 1996, p. 08). Tal legislação expressa de forma clara que formação do indivíduo deve ser para o exercício da cidadania, porém, o vetor que norteia essa discussão é a que tipo de cidadania estamos nos referindo.

Enquanto valor econômico a cidadania se referencia pela lógica da racionalidade econômica. (KUENZER, 2000; OLIVEIRA, 2001; SILVA JUNIOR, 2002; EVANGELISTA, SHIROMA, 2007; SAVIANI, 2007; RODRIGUES, 2008).

Kuenzer (2000), ao abordar especificamente o ensino médio, discute o caráter ideológico do discurso oficial do Estado que propõe e afirma que o então novo ensino médio teria uma nova abordagem que seria para a vida. $\mathrm{O}$ antigo modelo era para $\mathrm{o}$ trabalho, entendido como não vida, pois integrava educação e profissionalização numa mesma rede. Nesse sentido, a autora busca elucidar as concepções e intencionalidades decorrentes de interesses particulares, próprios das diferenças de classes. Contudo explica que a nova proposta imposta atende aos interesses da classe dominante que a apresenta como interesse universal, porém, o que ocorre é a expressão de uma concepção de educação orgânica ao modelo econômico em curso, ou seja, a versão nacional do processo globalizado de acumulação flexível.

Essa educação que atenda aos interesses do grande capital financeiro também é apontada por Oliveira (2001) quando destaca que as mudanças ocorridas globalmente devido ao capitalismo principalmente decorrentes da produção de caráter flexível afetaram diretamente a educação profissional e a educação do ensino médio brasileiro. Tais modificações são responsáveis pela mudança da vida humana nos mais diversos aspectos. Salienta que ocorre um conjunto de modificações que reformulam a estrutura política do Estado que busca melhorar a qualidade da mão de obra e propicia uma maior proximidade das modalidades educativas ao setor produtivo. O Estado, influenciado pelas agências multilaterais e pelo empresariado multinacional, não atua de forma a garantir a formação que priorize a confecção de um trabalhador autônomo e crítico.

Tal influencia propicia, inclusive reformas educacionais, é o que afirma Silva Junior (2002), que propõe compreender o que está subjacente na reforma educacional brasileira para seu nível médio e suas consequências na formação do ser social e mostrar as razões de ordem econômica que propiciaram suporte para as mudanças na esfera educacional. Explica que o então governo Fernando Henrique Cardoso propõe uma ação política para acelerar as mudanças sociais necessárias a nação, em face da matriz política, teórica e ideológica, caracterizada pela dependência do capital internacional.

Para isso, o governo publica um texto em que defende as reformas e as privatizações. Porém, trata-se de uma bela estória simplista de compreender as reformas institucionais, pressupondo harmonia, estabilidade contínua da situação social, que com alguns ajustes se tornaria democrática, justa e igualitária. Isso leva o autor a questionar: quais as derivações políticas da reforma educacional para o ensino médio e o que significada para a formação humana? Para tanto, expõe como se deu o movimento de construção de novo pacto social mundializado que propiciaria um "pan paradigma 
educacional" marcado com a ausência de debates das propostas para o ensino médio de caráter "infalível" dessas propostas.

E ainda culminou com um novo conteúdo histórico para a cidadania: centrada no individualismo; competitividade; adaptação; trabalho degradado; enfraquecimento de instituições e organizações políticas de mediação entre Estado e sociedade e finalmente a incapacidade de reivindicação do cidadão trabalhador. Igualmente, questiona: o que significam então as políticas para o ensino médio, decorrentes da reforma para esse nível de ensino e suas consequências para a formação do ser social? Essa é parte da condição de dimensão orgânica das reformas educacionais em todo o mundo que transforma o Estado forte no plano nacional e submisso no âmbito internacional.

Silva Junior (2002) ressalta as consequências para a formação humana diante da ideologia da instrumentalidade, adaptação e consenso presentes no ensino médio, que levam os jovens a desacreditarem da escola enquanto meio para a ascensão social e inserção no mercado de trabalho. Contraditoriamente as classes médias e as elites fogem da escola pública, constituída apenas para os desvalidos sociais. Assim, o ensino médio tende a acentuar as desigualdades sociais e não propicia a equidade, levando cada indivíduo a se conformar com sua classe social. Conforme o autor, nunca a educação pública fora tão perversa. Ele conclui: as políticas públicas para o ensino médio formam o cidadão do século XXI produtivo, útil, mudo, competitivo e solitário.

Nesse sentido, podemos nos questionar qual o papel do professor nessa formação, para tanto recorremos aos estudos de Evangelista; Shiroma (2007), que procuram entender a especificidade do trabalho do professor na sociedade brasileira contemporânea, ou seja, entender por que o professor é construído como causa e solução dos problemas educacionais frente à reforma do Estado no Brasil, ligada aos organismos internacionais para a educação do início do século $\mathrm{XXI}^{3}$.

$\mathrm{Na}$ opinião das autoras, os organismos internacionais influenciam de forma objetiva as políticas e práticas educativas brasileiras e explicitam as ideias-força que compõem o ideário da AGEE , que tem como eixo central a governabilidade dos Estados e do planeta e a necessidade de manter o sistema capitalista. Explicam que ocorre um processo de "conformação" docente, por meio do controle político-ideológico sobre o magistério que envolve sua formação e sua atuação profissional. Assim, a reforma dos anos 1990 e seu prosseguimento para o século XXI atingiu todas as esferas da docência: currículo, livro didático, formação inicial e contínua carreira, certificação, lócus de formação, uso das tecnologias da informação e comunicação, avaliação e gestão. Essas políticas conduzem o trabalho docente à intensificação e à precarização.

O que se pretende com isso é que nem todos os estudantes aprendam apenas passem alguns anos de sua vida na escola a fim de serem passíveis de controle social, inculcação ideológica e alguma formação geral para a aquisição de competências para o trabalho. Apontam outras divergências: a educação é fundamental para o avanço do país, mas o Estado não deve gastar muito, assim, a eficiência e a eficácia é fundamental, mas que isso não implique em aumento do quantum destinado ao financiamento da Educação. Nesse sentido, o importante é que a escola tenha autonomia financeira, faça parceria, convoque a comunidade, arrecade recursos, para, com isso, modificar a escola e adequá-la ao orçamento possível. A escola é entendida como um setor produtivo, assim, a repetência é entendida como desperdício, daí a necessidade da política de classes de aceleração e inclusão, visando a otimizar o recurso professor. As autoras criticam a redução de custos com o salário do professor e a insistente recomendação da UNICEF $^{4}$ em contratar professores baratos. 
As autoras anunciam uma possível afirmação, a de que o professor desejado pelos reformadores admitiria ser controlado e perder sua autonomia no que toca aos objetivos e sentido de sua ação. Afirmam que o desafio está em professores capazes de criar a capacidade coletiva, apropriar-se da dimensão pública da escola e do conhecimento como direito social e lutar pela socialização de bens culturais e materiais. E convidam os professores a rejeitar o projeto social excludente em andamento, que brilha com o lema "Educação para Todos", conclamando os professores a dizerem que preferem ser professores obstáculos.

Mas e quanto ao ensino fundamental? Saviani (2007), explica que no ensino fundamental a relação entre trabalho e educação é implícita e indireta. Já no ensino médio a relação entre educação e trabalho é explícita e direta e deve propiciar aos alunos o domínio dos fundamentos de diversas técnicas utilizadas na produção, formando politécnicos.

\section{Considerações finais}

A cidadania forjada por uma educação voltada para o mercado reforça os seus sentidos como valor econômico, conduzido por um discurso de favorecer a inserção social e a melhoria do nível de qualidade dos menos favorecidos, entretanto de forma implícita traz consigo os interesses velados ou ocultos que não garante a sua validação em sentido pleno, uma vez que somente parcelas da dimensão da cidadania são colocados em evidência. E o restante? O restante a lógica capitalista coloca como parte da agenda para renegociação com "dados valores" que em nada modificam a estrutura social.

Assim, podemos entender que o espaço escolar é palco do processo contraditório da sociedade capitalista, ao que Rodrigues (2008) afirma que esta é condicionada e condicionadora da reprodução da sociedade burguesa e das suas próprias contradições classistas existentes nessa ordem, ou seja, a manutenção e reprodução da sociedade é o objetivo número um da escola no capitalismo. Nesse sentido, impõe-se a necessidade de se compreender a ruptura com tal estrutura como um importante componente na construção de uma nova sociedade e de uma nova escola.

Daí a necessidade de compreensão do processo de formação do estudante para o exercício da cidadania. Rememorando Mészáros (2005, p. 12) “[...] uma educação para além do capital deve, portanto, andar com mãos dadas com a luta por uma transformação radical do atual modelo econômico e político hegemônico".

\section{Referências}

ALVES, G. Dimensões da Reestruturação Produtiva: ensaios de sociologia do trabalho. $2^{\text {a }}$ edição. Londrina: Práxis; Bauru: Canal 6, 2007.

BALL, S. J. Sociologia das politicas educacionais e pesquisa critico-social: uma revisão pessoal das políticas educacionais e da pesquisa em política educacional. In: BALL, S. J.; MAINARDES, J.(Orgs.). Políticas educacionais: questões e dilemas. São Paulo: Cortez, 2011, p. 21-53.

BRASIL. Lei 9394, de 20/12/1996. Estabelece as Diretrizes e Bases da Educação Nacional. Brasília, 1996. Disp. em:

<http://www.planalto.gov.br/ccivil_03/leis/L9394.htm>. Acesso em: 22 de Out. 2011. 
BRASIL. Constituição (1988). Constituição da República Federativa do Brasil. Brasília, DF: Senado Federal. Disp. em: < http://www.senado.gov.br/legislacao/const/con1988/CON1988_05.10.1988/CON1988.pdf >. Acesso em 16 de fev. 2010.

BENEVIDES, M.V. A questão social no Brasil: os direitos econômicos e sociais como direitos fundamentais, 2007, paginação irregular. Disponível em <http://www.hottopos.com/vdletras3/vitoria.htm>. Acesso em 30 de dez. 2012.

CARVALHO, E. J. G. de. Reestruturação produtiva, reforma administrativa do estado e gestão da educação. Educ. Soc. [online]. 2009, vol.30, n.109, p. 1139-1166. Disponível em < http://www.scielo.br/scielo.php?script=sci_arttext\&pid=S0101$73302009000400011 \&$ lang=pt $>$. Acesso em 22 de Out. de 2012.

EVANGELISTA, O; SHIROMA, E. O. Professor: protagonista e obstáculo da reforma. Educação \& Pesquisa. vol. 33, n. 3. São Paulo, Set./Dez, 2007, p. 531-54. Disponível em $<$ http://www.scielo.br/scielo.php?script=sci_arttext\&pid=S151797022007000300010\&lang=pt $>$. Acesso em 18 de mar. de 2010.

FERREIRA JR., A; BITTAR, M. A educação na perspectiva marxista: uma abordagem baseada em Marx e Gramsci. Interface - Comunicação, saúde, educação. (Botucatu) vol.12, n. 26, Jul./Set, 2008, p. 635-646. Disponível em < http://www.scielo.br/pdf/icse/v12n26/a14.pdf >. Acesso em 25 out. 2009.

FRIGOTTO, G. Escola e trabalho numa perspectiva histórica. Contradições e controvérsias. Sísifo. Revista de Ciências da Educação, Lisboa, n. 09, 2009, p. 129-136. Disponível em <http://sisifo.fpce.ul.pt/?r=23\&p=132 >. Acesso em: 12 de Mar. 2012.

GALBRAITH, J.K.; MENCHIKOV, S. Capitalisme, communisme et coexistence: de l'antagonisme à l'entente / tradução de L'américain par Lionel Dahan/ Paris: InterÉd , 1988.

HARVEY, D. Condição pós-moderna. Tradução de Adail Ubirajara Sobral e Maria Stela Gonçalves. 9. ed. São Paulo: Loyola, 2000.

HOBSBAWM, E. J. Mundos do trabalho. Tradução de Waldea Barcellos e Sandra Bedian.. São Paulo: Paz e Terra, 2005.

KUENZER, Z. A. O ensino médio agora é para a vida: entre o pretendido, o dito e o feito. Educação \& Sociedade. v.21, n.70, Campinas, Abr, 2000, p. 15-39. Disponível em < http://www.scielo.br/pdf/es/v21n70/a03v2170.pdf >. Acesso em 13 de Mar de 2010.

LIMA, P. G. Universidade brasileira numa perspectiva universal, humana e democrática. São Paulo: Annablume, 2012.

LOMBARDI, J. C., SAVIANI, D. \& SANFELICE, J. L. (Eds.). Capitalismo, Trabalho e Educação. Campinas, SP: Autores Associados, 2002.

MARTINELLI, M. L. Serviço Social: identidade e alienação. São Paulo: Cortez, 2006.

MARTINS, H. H. T. de Souza. O processo de reestruturação produtiva e o jovem trabalhador: conhecimento e participação. Tempo social. [online]. 2001, vol.13, n.2, p. 6187. Disponível em < http://www.scielo.br/scielo.php?script=sci_arttext\&pid=S0103$20702001000200004 \&$ lang=pt $>$. Acesso em 22 de Outubro de 2012.

MARSHALL, T. H. Cidadania, classe social e status. Tradução de Meton Porto Gadelha. Rio de Janeiro: Zahar Editores, 1967. 
MARX, K. O Capital. Tradução de Regis Barbosa e Flávio R. Kothe. Volume I. São Paulo, Abril, Cultural, 1983.

MÉSZAROS, I. A educação para além do capital. Tradução de Isa Tavares. São Paulo: Boitempo, 2005.

OLIVEIRA, R. A divisão de tarefas na educação profissional brasileira. Cadernos de Pesquisa. n.112, São Paulo. Mar. 200, p. 185-203. Disponível em < http://www.scielo.br/scielo.php?script=sci_arttext\&pid=S010015742001000100010\&lang=pt>. Acesso em 13 de Mar de 2010.

PNUD. Relatório sobre o Desenvolvimento Humano de 2007/2008. New York: Programa de Desenvolvimento das Nações Unidas, 2007.

RODRIGUES, D. A. Escola em disputa: a contribuição e limites de Marx sobre a educação. Trabalho \& Educação - vol.17, no 3, set/dez , 2008, p. 117-130. Disponível em < http://www.portal.fae.ufmg.br/seer/index.php/trabedu/article/viewFile/352/317>. Acesso em 15 de março de 2010.

SAVIANI, D. Trabalho e educação: fundamentos ontológicos e históricos. Revista Brasileira de Educação. Vol 12, no. 34, Rio de Janeiro, Jan./Abr. 2007, p. 152-165. Disponível em < http://www.scielo.br/scielo.php?script=sci_arttext\&pid=S141324782007000100012> Acesso em 15 de abr. de 2010.

SILVA JUNIOR, J. R. Mudanças estruturais no capitalismo e a política educacional do governo FHC: o caso do ensino médio. Educação \& Sociedade. n .80 . Campinas, Set. 2002. 23 v., p. 201-233. Disponível em <http://www.scielo.br/scielo.php?script=sci_arttext\&pid=S0101$73302002008000011 \&$ lang=pt >. Acesso em 15 de março de 2010.

ZANARDINI, I. M. S.; ORSO, P. J. (Orgs). Estado, Educação e Sociedade Capitalista. Cascavel : Edunioeste, 2008.

ZIBAS, D. M. L. O reverso da medalha: os limites da administração industrial participativa. In: CARLEIAL, Liana \& VALLE, Rogério (Orgs.). Reestruturação produtiva e mercado de trabalho no Brasil. São Paulo, Hucitec-Abet, p. 122-139, 1997.

\section{Notas}

\footnotetext{
${ }^{1}$ Mestre em Educação pela Universidade Federal da Grande Dourados (UFGD). Docente no Curso de Serviço Social no Centro Universitário da Grande Dourados - UNIGRAN. Email: lilian.candia@ hotmail.com ${ }^{2}$ Docente do PPGED da UFSCAR-Campus Sorocaba. E-mail: paulolima@ufscar.br

${ }^{3}$ Para isso, as autoras utilizam-se do conceito da Agenda Globalmente Estruturada para a Educação (AGEE), proposto por Roger Dale (2001 apud EVANGELISTA e SHIROMA, 2007). O corpus da análise está em três grandes projetos para a Educação na América Latina e Caribe: o Proyecto Regional de Educación para América Latina y el Caribe - (PREALC), patrocinado pela UNESCO (United Nations Educational Scientific and Cultural Organization), com previsão de encerramento para 2017; o Plan de Cooperación, resultante das Cumbre Iberoamericana de Educación, patrocinadas pela Organización de los Estados Iberoamericanos para la Educación, la Ciencia y la Cultura (OEI); e os Proyectos hemisféricos en educación, patrocinados pela Organização dos Estados Americanos - OEA.

${ }^{4}$ UNICEF - Fundo das Nações Unidas para a Infância (em inglês United Nations Children's Fund).
}

Recebido em abril-13

Aprovado em outubro-13 